\title{
DIE PRINSIPIËLE PLEK VAN OUDIOVISUELE MIDDELE IN DIE EREDIENS
}

\author{
J.C. MÜLLER
}

Tot $70 \%$ van wat ons sê, sê ons sonder woorde! Ons gebare, houding, gesigsuitdrukking, kleredrag, stemtoon, selfvertroue of gebrek daaraan, oogbeweging - die duur van 'n kyk, die posisie van die oë (m.a.w. loer ek, of gluur ek, of kyk ek met deernis), ensovoorts, dra alles betekenis oor en sê geweldig baie. Wanneer daar gepreek word is dit nie slegs die inhoud wat van belang is nie. In kommunikasie gaan dit wesenlik om vier sake:

1. Die inhoud van wat gesê word

2. Die toon waarin dit gesê word

3. Die doen of aktiwiteit

4. Die sosiale situasie waarbinne gekommunikeer word. ${ }^{11}$

Tot dusver was ons geneig om in die prediking slegs op die eerste klem te lê en die ander aspekte heeltemal te verwaarloos. Dit terwyl die ander aspekte van kommunikasie ' $n$ hele wêreld van moontlikhede open. J.M. Smith het byvoorbeeld in ' $n$ artikel in "Instructa '78" gewys op die

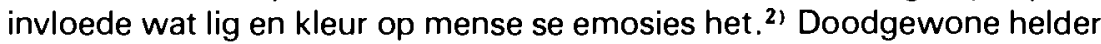
ligte in 'n vertrek wat bloot sigbaarheid ten doel het, noem hy "flat lighting" en beweer dat dit ook emosioneel plat is. Terwyl lig aan die ander kant so aangewend kan word dat dit in samespel met ander faktore emosies kan beinvloed. So is daar ook "warm" en "koue" kleure wat emosies dienooreenkomstig beïnvloed. Baie van ons kerkgeboue is ontwerp sonder dat daar werklik rekening gehou is met hierdie wesenlike aspekte van die kommunikasieproses. Die gevolg is dat preekkommunikasie inderwaarheid belemmer word.

Die visuele het ' $n$ verbysterende, byna angswekkende aantrekkingskrag. Ondersoeke het aan die lig gebring dat alles wat vinnig beweeg, soos die beelde op TV, tot ' $n$ hoër psigiese opwinding aanleiding gee. lemand sit doodgewoon voor die TV, maar intussen is sy asemhaling, hartklop en polsslag besig om te verander. Die blote kyk veroorsaak emosionele opwinding en daarom is dit oor die algemeen glad nie maklik om ' $n$ televisiestel af te skakel nie. ${ }^{3}$ ' Die magnetiese invloed van die visuele sal in ons benadering tot die prediking ook baie meer verreken moet word. 
Daar moet andersyds ook geen illusies bestaan oor die probleem wat die tradisionele preek het met die verkry en behou van mense se aandag nie. In 'n onlangse empiriese ondersoek is bevind dat minstens $30 \%$ van die kerkgangers se aandag tydens die diens heeltemal afdwaal." Hierdie syfer is waarskynlik nog meer negatief in die lig van die feit dat mense nie geredelik erken (selfs nie in 'n anonieme vraelys nie) dat hulle aandag afgedwaal het nie.

Met hierdie paar inleidende opmerkings is dit reeds duidelik dat kommunikasie multidimensioneel van aard is. In die oordra van die Goddelike boodskap is dit soveel te meer waar. Hier gaan dit immers om 'n boodskap wat die hele mens betrek. Daarom kan hierdie kommunikasie nie slegs op die verbale en intellektuele vlak aangepak word nie. Predikante behoort groot erns te maak met die vraag of hulle deur middel van hulle preke daarin slaag om betekenisse en veral geloofsinhoude oor te dra. Hoewel die gebruik van oudiovisuele middele nie 'n towerformule behels nie, bied die meerdere gebruik daarvan groot moontlikhede vir meer suksesvolle preekkommunikasie.

\section{OUDIOVISUELE MIDDELE WAT BRUIKBAAR IS IN DIE EREDIENS}

Oudiovisuele media kan in twee kategorieë verdeel word. Eerstens kan dit aangewend word as "instructional medium". Dit beteken die onderrig vind plaas deur die medium self. Die medium tree in die gevalle dus selfstandig op. Die tweede kategorie is die media wat gebruik word as hulpmiddele in die onderrigsituasie, met ander woorde dit word begelei deur die verbale.5) Albei hierdie vorme is reeds ingeburger in ons eredienste. Eersgenoemde funksioneer in al die vaste simbole wat in kerkgeboue aangebring word (bv. die doopfont, die kruis, die duif, ens). Laasgenoemde funksioneer weer in die sakramente waar die teken deur verduidelikende woorde begelei word. Op hierdie terrein het daar egter in die jongste jare ' $n$ wêreld van moontlikhede oopgegaan. Afgesien van nuwe tegniese hulpmiddels wat op die mark verskyn het, is die gebruik van die drama in hierdie verband ook ontgin. Hieronder volg ' $n$ lys van media wat in die eredienssituasie bruikbaar is (die met ' $n$ * is myns insiens veral geskik):

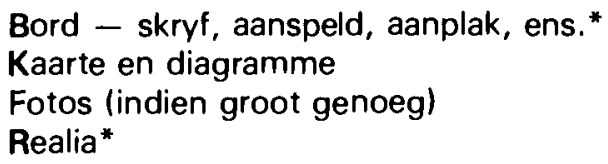


Skyfies, geprojekteer

Deursigbeelde (truprojektor)*

Rolprent

Video*

Blaaibord*

Bandspeler

Dramatisering van Bybelste stof*

Bibliodrama*

Dit val nie binne die bestek van hierdie artikel om elkeen van hierdie media in besonderhede te bespreek nie. In die BIBLIODRAMA het ons egter met ' $n$ relatief onbekende verskynsel te doen en daarom net ' $n$ paar sinne daaroor. Hierdie medium is in 1967 vir die eerste keer deur J. Zacharias gebruik. Dit moenie verwar word met die dramatisering of naspeel van die Bybelse verhaal nie. In die bibliodrama het jy te doen met 'n kombinasie van die Bybelse gegewens en die hier-en-nou-belewing van die spelers en kykers. Die deelnemers van die hede identifiseer met die Bybelse verhaal en dit word ' $n$ ervaring in die hede. Die resultaat is ' $n$ eie oorspronklike dramatiese voorstelling wat die Bybelse boodskap in en vir die hede uitbeeld. ${ }^{6}$ )

\section{WEERSTAND TEEN OUDIOVISUELE MIDDELE}

By sommige (teoloë) is daar ' $n$ weerstand teen die gebruik van hierdie media in die erediens. Die Goddelike handelinge, word gesê, is basies onvoorstelbaar. Die werklikheid van God bestaan in die geloof en nie in die aanskoue nie. God is die "Ganz Andere". Die oudiovisuele middele is dus eintlik wesentlik vreemd aan die godsdiens. Die openbaringswoord word hierdeur tot "religiosen Bildungsgut" gemaak, dit word beroof van sy nie-wêreldlike, ewige aanspraak." Dit wat Goethals noem "crosscultural desire to find in religious communication the invisible in the visible, the intangible in the tangible ${ }^{\prime \prime},{ }^{8)}$ moet dus teengewerk word en die vraag na oudiovisuele media afgewys word as 'n sondige neiging. Ons ken ook die kerkgeskiedenis, hoedat die beelde in die Roomse kerk uiteindelik so belangrik geword het dat dit as die "boeke van die leke" bestempel is - iets waarteen die Hervormers hewig in opstand gekom het. Die gevolg is dat simbole en ander visuele uitbeeldinge in die kerke van die Hervorming maar stief behandel is. Verskeie teoloë het tekste soos Rom. 10:17 en Heb. 11:1 beklemtoon om daarmee te sê dat dit in die geloof om die onsigbare gaan en dat die hoor Bybelse voorrang geniet bo die sien. ${ }^{9 \text { ) }}$ 
Hierdie afwysende houding teenoor die visuele is egter foutief. Die verkondiging van die Goddelike Woord is tegelyk ook 'n menslike woord wat net soos alle ander woorde onder die eis van verstaanbare spraak staan. Verder is die visuele nie 'n wesenlik ander vorm van woordkommunikasie as die ouditiewe nie. Dit staan daarom nie teenoor 'n teks soos Rom. 10:17 nie. In hierdie teks is daar in elk geval nie sprake van 'n voorrang van die gehoor bo die gesig nie, eerder dat God die prediking as middel gebruik om mense tot geloof te bring. Paulus is immers nie besig om enigsins die gehoor teenoor die gesig af te speel nie.

In die oudiovisuele gaan dit juis nie om òf die gehoor òf die gesig nie, maar om albei. Om die waarheid te sê, dit gaan om al die mens se sintuie wanneer sulke media gebruik word. Natuurlik kan die gesproke woord alleen ál die sintuie betrek en aktiveer, veral wanneer daar van aanskoulike of beeldryke taal gebruik gemaak word. Dit moet egter beklemtoon word dat oudiovisuele materiaal die waarde het dat dit die moontlikhede van sensoriese stimuli heelwat vergroot. ${ }^{10)}$ Hoe groter die stimulering van sintuie, hoe groter die moontlikheid om aanskouing te bewerk by die hoorders. Aanskouing het te doen met al die sintuie en het betrekking op die innerlike verwerking of voorstellings. "' Selfs ingewikkelde en abstrakte begrippe word na die sintuie teruggevoer om aanskouing van die saak moontlik te maak. Ons kry dikwels voorbeelde hiervan in die Bybel. Om te vertel hoe groot die vergewing en liefde van God is, maak die Psalmdigter gebruik van die mens se belewing van waar die son opkom en waar dit ondergaan. Om die omvang van God se verbondsbeloftes te verduidelik, word die sintuiglike ervaring van die sand van dia see en die sterre van die hemel bygetrek. Luther het hierdie waarheid ingesien en gesê dat as jy iets hoor en dink, dit onmoontlik is om nie in jou hart ' $n$ beeld daarvan te maak nie. Ons kan niks sonder ' $n$ beeld verstaan of selfs daaroor dink nie. ${ }^{12}$ )

Die beswaarmakers wat die ouditiewe teen die visuele probeer afspeel, hou skynbaar ook nie rekening met die feit dat reeds die geskrewe woord wat lankal so 'n vastrapplek in die erediens het, ook 'n visuele medium is nie. Hulle hou ook nie rekening met die feit dat elke mens ook ' $n$ eie aanskouing oor sake met hom meebring nie. So is daar 'n mens se beskouing (aanskouing) oor moederliefde, gesag, tugtiging en nog baie ander. Die prediking is op hierdie voorstellings aangewese. ${ }^{13 \prime}$ Om werklike visuele materiaal te gebruik, sluit maar net aan by dit wat in elk geval onsigbaar by mense aan die gebeur is.

\section{DIE WAARDE VAN OUDIOVISUELE MIDDELE}

Goed gekose en behoorlik gebruikte media het die volgende waarde: 
1. Dit kan help om korrekte eerste indrukke te gee.

2. Dit kan belangstelling stimuleer. Die fasinerende van ' $n$ beeld is dat dit onmiddellik emosioneel aanspreek. Die emosionele resonans by die hoor van woorde is baie geringer as wanneer dit ook verbeeld word. 14)

3. 'n Beter verstaan word gestimuleer.

4. Dit bied die moontlikheid van variasie in metodes van oordrag.

5. Tydsekonomie word hierdeur bevorder.

6. Dit bevorder intellektuele nuuskierigheid.

7. Dit help om verbalisme (die betekenislose herhaling van woorde 'n groot gevaar in godsdiens) te verminder.

8. Dit help om dinge langer te onthou.

9. Dit gee aan die prediker die geleentheid om die ervaringshorison by kerkgangers te verbreed. ${ }^{15}$ )

\section{BEGINSELS VIR DIE KORREKTE (EFFEKTIEWE) GEBRUIK VAN OUDIOVISUELE MEDIA IN DIE EREDIENS}

1. Dit gaan in die erediens nooit primêr om nuwe media nie, maar om nuwe mense. Of beter gestel: dit gaan in die erediens om God - God wat self kanale vind om sy Evangelie in ons ore en harte te laat weerklink. Nie die medium is deurslaggewend nie, maar die inhoud. Tog vereis die inhoud telkens nuwe media. ${ }^{16)}$ Enersyds mag ons nie ons hoop vestig op allerlei interessante hulpmiddele asof dit towerstaffies is nie; andersyds mag ons nie die werklikheid van God se werking ten spyte van menslike pogings as 'n alibi aanwend vir swak kommunikasie nie.

2. Beeldende onderrigmateriaal het slegs 'n dienende of begeleidende funksie. Dit kan die aanskoulike woord nooit vervang nie. Hans van der Geest moet gelyk gegee word as hy sê: "Looking at people or showing them something never attains the degree of personal engagement that speaking to them does ...". ${ }^{17}$ Tog kan visuele materiaal die gesproke woord wonderlik begelei en dien. Een medium van kommunikasie kan nie 
verhef word tot die absolute nie. Suksesvolle kommunikasie behels die gebruikmaak van 'n kombinasie van media.

3. Oudiovisuele middele kan nooit vergoed vir gebrekkige prediking nie. Die gebruik van hierdie middele bied op sigself geen waarborg dat enige voordrag gaan slaag nie. 'n Swak preek kan nie verbeter word deur van 'n truprojektor gebruik te maak nie. Inteendeel, 'n swak preek word eerder verder verswak deur van sulke media gebruik te maak, want dan word die gebrekkige kommunikasie op soveel meer vlakke ervaar. Dan raak Shakespeare se woorde in Macbeth op die prediker van toepassing: "a tale told by an idiot, full of sound and fury, signifying nothing"! Die wanopvatting bestaan ook soms dat die gebruik van oudiovisuele media die preekmaakproses vergemaklik en bespoedig. Die teendeel is egter waar.

4. Wanneer hierdie media slegs ter wille van interessantheid of om aandag te trek gebruik word, mis dit die doel. Daar word soms naief geglo dat die blote sien van 'n prent of voorwerp, in die toekoms werklike waarde sal hê. So eenvoudig werk dit nie. In elk geval het die prediker die taak om mense met die evangelie te konfronteer en nie net iets vir hulle te wys nie. Natuurlik kan die wys 'n belangrike funksie vervul in die konfrontasieproses, maar dan moet dit in lyn staan met die doel wat die prediker wil bereik en nie maar net interessant wees en daarom aandag op sigself vestig nie.

5. In aansluiting by die vorige punt moet beklemtoon word dat niewesenlike of newesake nie verbeeld moet word nie. Die prediker moet vir homself bepaal wat sy doel is met die preek en wat hy daarmee wil bereik. Hierby moet die media wat hy gebruik, aansluiting vind. Indien dit nie die geval is nie, is sy hulpmiddele teenproduktief en lei hy miskien op ' $n$ heel effektiewe wyse die mense se aandag af van sy hoofboodskap. ${ }^{18}$ '

6. Onderbenutting is beter as oorbenutting. Enige medium wat te veel gebruik word, bereik juis die teenoorgestelde as wat die bedoeling is, naamlik onuitspreeklike verveling en irritasie. Wanneer iemand jou verveel met sinnelose herhaling in wat hy sê, is dit al erg genoeg, maar as hy jou dan ook op die visuele vlak hierby betrek, word dit een te veel. Oudiovisuele middele moet spaarsaam gebruik word om effektief te wees.

7. Die regte medium moet vir ' $n$ bepaalde situasie gekies word. Om dit te kan doen moet die volgende drie sake in gedagte gehou word: 
*Die produksiekwaliteit van die materiaal.

* Die doel wat jy wil bereik.

* Die karaktertrekke of eienskappe van die teikengroep. Die grootte en ontwerp van die kerkgebou, die ouderdom van die gehoor, die ontwikkelingspeil van die gehoor, die sigbaarheid van die betrokke medium, ensovoorts sal dus alles deeglik in berekening gebring moet word by die keuse van 'n hulpmiddel.

\section{Notas}

1. J.C. Muller, Die Homilie as wyse van eietydse prediking, ongepubliseerde proefskrif, Universiteit van Pretoria 1983, 84.

2. J.M. Smith, "Encoding the Message", in: Instructa '78 onder redaksie van R. Eberlein, P.J. van Zyl en B.J. Venter, Durban 1979, 169.

3. H. Sturm, "Forum: Immer neue Medien", Diakonie Jahrgang 11/1, Jan/Feb 1985 , $28-34$.

4. Sturm, a.w., 28-34.

5. H.P. Fourie, "Principles of Media Selection", in: Instructa '78 Durban 1979, 134.

6. R. goeden, "Zoek de Farao in jezelf", in Praktische Theologie, 1983/2, 173-177. Vgl. ook J. Lap, "Bibliodrama; Inspelen op Gods tegenspel", Praktische Theologie, 1983/2, 163-172; F. Rohrer, "Ausschnittsberichte aus einem bibliodrama", Wissenschaft und Praxis in Kirche und Gesellschaft Jahrgang 68 Heft 4, April 1979, 144-151; E.N. Warns, "Spielen mit Religionslehren", Wissenschaft und Praxis in Kirche und Gesellschaft, Jahrgang 68 Heft 4, April 1979, 157-169.

7. E. Bochinger, Anschaulicher Religionsenterricht, Stuttgard ${ }^{2} 1967,21$.

8. G. Goethals, "Religious Communication and Popular Piety", Journal of Communication, 3511) Winter 1985, 149-156.

9. Z. Rittersma, Het dramatiseren van Bijbelse geschiedenissen door jeugdigen, Leiden 1972,128 en 129.

10. C.W.H. Erickson, Fundamentals of teaching with Audiovisual Technology, USA $1965,7$.

11. E.V.E. Pretorius, "Die Gebruik van Skyfieprogramme in die Onderrigsituasie"; in $/ n$ structa'78 Durban 1979, 187.

12. Bochinger, a.w. 1967, 128.

13. Bochinger, a.w. 1967, 32.

14. I. Baldermann en G. Kittel, Die Sache des Religionsunterrichts, Göttingen 1975, - 114.

15. Erickson, a.w. 1965, 12; vgl. ook O. Knodler, "Haben wir die Medien, die wir brauchen?", Diakonie, Jahrgang 11/1, Jan/Feb 1985, 9-14; B. Morgan, G.E. Holmes en C.E. Bundy, Methods in Adult Education, Illinois 1976, 187.

16. K.H. Neukamm, "Pia desideria", Diakonie, Jahrgang 11/1, Jan/Féb 1985, 2-4.

17. H. van der Geest, Presence in the pulpit, Atlanta 1981, 46.

18. J. Lizamore, "Selection of Media", Instructa '78 Durban 1979, 143; vgl. ook E. Bochinger, a.w. 1967, 131. 


\section{Addisionele Bibliografie}

1. A.C. Barnard, Die Erediens, Pretoria 1981.

2. W. Hammer, "Die Sprache der Verkundigung im Prisma moderner Literatur", in: Die Predigt als Kommunikation, Herausgegeben von Jurgen Roloff, Stuttgart 1972.

3. W.G. Tillmans, "De nieuwe media en de kerken", Praktische Theologie, 1983/2, $127-143$. 